\title{
Medical publishing during the COVID-19 pandemic: then and now
}

\author{
Richard C. Becker ${ }^{1} \cdot$ Christoph Bode $^{2}$ \\ Accepted: 24 February 2021 / Published online: 9 March 2021 \\ (C) The Author(s), under exclusive licence to Springer Science+Business Media, LLC, part of Springer Nature 2021
}

\section{Introduction}

The earliest cases of SARS-CoV-2 causing COVID (CO for 'corona,' 'VI' for 'virus,' and 'D' for disease)-19 occurred around 1 December 2019 [1]. Later in the month, the World Health Organization (WHO) China Country office received notification of cases of pneumonia of unknown cause detected in Wuhan City, Hubei Province of China. Viral analysis of samples [2] matched the genome from lineage $\mathrm{B}$ of the genus beta-coronavirus showing great than $85 \%$ identity with a bat SARS (severe acute respiratory syndrome)-like $\mathrm{CoV}$. The international WHO received notification between 31 December 2019 and 3 January 2020 of 44 patients with pneumonia of unknown etiology. On 11 January 2020, the Chinese National Health Commission identified the source of exposures at a seafood market in Wuhan City (Huanan Seafood Wholesale Market) (reviewed in Becker RC) [3]. At the time of this writing, 29 January 2021 , there have been 113,000,000 confirmed cases of COVID-19, including 2.5 million deaths, reported to the WHO (Fig. 1) (www.who.int/covid;accessed 6 March 2021).

\section{The tenet of scientific publishing}

The promotion of peer review in science and medicine, representing the bedrock of scholarly exchange dates back to 6 March 1665 when the Royal Society of London (currently known as the Royal Society) established the first scientific journal-Philosophical Transactions (Reviewed in Kelly) [4]. Despite many early critics, the founders to include the Society's first secretary, Henry Oldenberg, felt strongly that

Richard C. Becker

Richard.becker@uc.edu

1 Heart, Lung and Vascular Institute, University of Cincinnati College of Medicine, 231 Albert Sabin Way ML 0542, Cincinnati, OH 45267, USA

2 Heart Center, Freiburg University, Freiburg, Germany peer review represented the best means to maintain scientific integrity in published materials. The available information suggests that the secretary himself undertook the initial peer-reviews.

The medical and scientific communities continued to strive for a process that would yield information of the highest quality. The "Medical Essays and Observations" published by the Royal Society of Edinburgh in 1731 adopted a peer review process summarized as follows "Memoirs sent by correspondence are distributed according to the subject matter to those members who are most versed in these matters. The report of their identity is not known to the author." In this particular instance, the peer reviewers were Society members. The Royal Society of London furthered the spirit of peer review in 1752 by forming a "Committee on Papers". The function of the committee was to review abstracts of manuscripts and "vote by secret ballot without discussion" on what to publish in Philosophical Transactions. By 1832, the Royal Society sought independently written referees' reports to ensure that more expertise informed the Committee on Papers in its editorial decision-making. Thereafter, refereeing conducted by authorities in a given field of study became a signature and established norm for medical publishing [5-7].

\section{Enter the pandemic of $\mathbf{2 0 2 0}$}

In an unprecedented fashion, the medical and scientific communities encouraged strongly by the public, federal governments and global health organizations sought a means to understand SARS-COV-2 and its heterogeneous, yet clearly life-threatening phenotype, COVID-19 (reviewed in Becker RC) [8]. The questions were many and highly complex with societal, cultural and economic implications. How would clinicians, scientists and leaders around the world respond? What role would publishers of medical and scientific content play? Where would the long-standing and time-honored relationships between academia, publishers, industry (pharmaceutical, device), federal and non-profit organizations stand? 
Fig. 1 Cases of COVID-19 reported to the World Health Organization

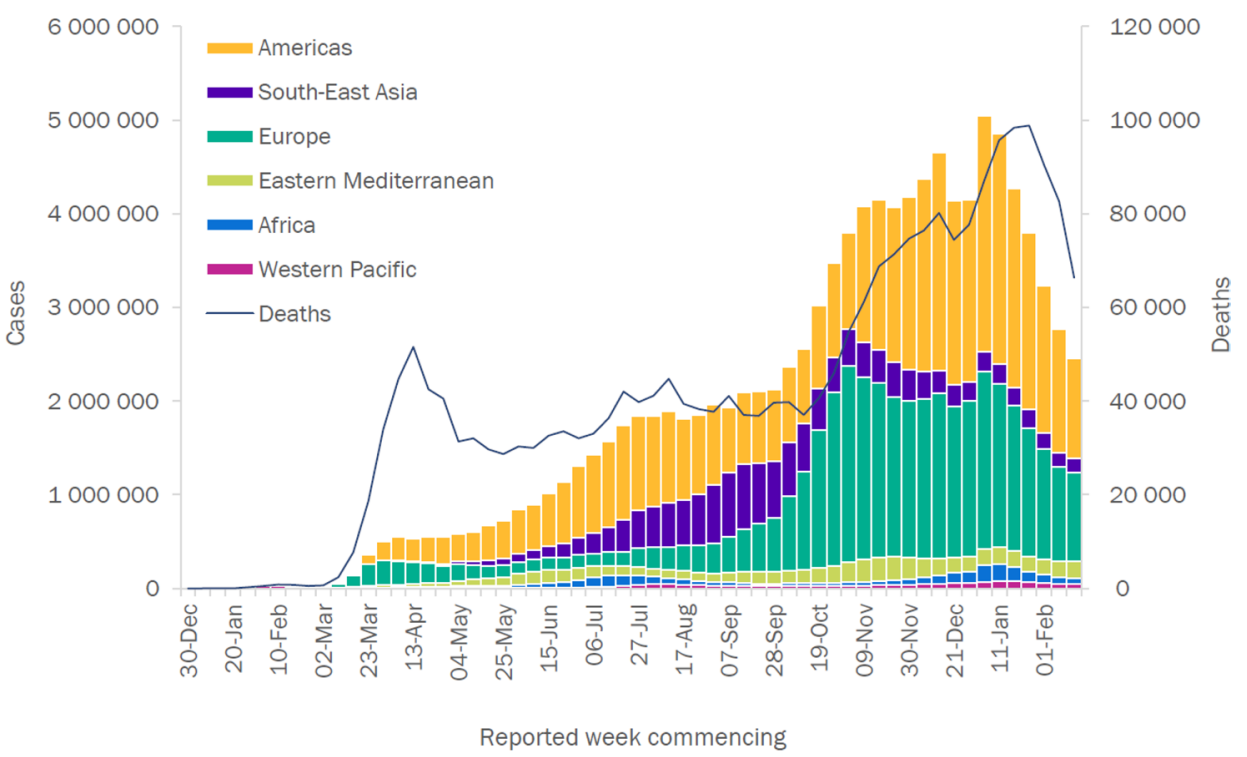

Legend: The number of new cases of COVID-19 continues to rise in many parts of the world, particularly in the Americas. World Health Organization 21 February 2021. www.who.int/covid.
How would they function in a coordinated fashion to inform one-another and literally billions of people on the planet in need of answers, guidance, effective treatments and safe vaccines to quell the raging sea of SARS-COV-2? The answer of course is, "in a progressive, meticulous, coordinated, transparent, and honest fashion".

\section{Initial response}

History has documented that humans respond to unexpected or unexplainable events reflexively and at times viscerally, beginning with raw observations, followed by an assessment, and in time seek evidence-based explanations [9-11]. Based on one's background, perspectives, training, expertise, circumstances and resources, explanations may be sought through well-formulated hypotheses, past experiences, similar observations made by trusted colleagues or documented in the annals of medicine, or a virtual word of mouth in conferences, seminars, podcasts, social media or mainstream media outlets.

Observations dominated the initial COVID-19 experience-first of a modest number of affected patients, followed by increasingly large patient cohorts from China, Europe and the United States. Simultaneously, clinical and laboratory observations became increasingly detailed and included vital elements of necropsy observations that connected four critical "dots"- the SARS-COV-2 virus and resulting infection; presenting signs, symptoms and laboratory findings; type, depth and extent of specific organ involvement; and the early course of disease. Treatment beyond supportive care, advanced mechanical therapies where available and for documented secondary bacterial infections was unknown and untested.

An observational approach to understanding a disease, and certainly one as complex as COVID-19, would be expected to foster incremental gains in knowledge. Indeed, observational studies performed longitudinally with scientific rigor have contributed significantly to our understanding of human disease and its natural history (reviewed in Liebman) [12]. The medical and scientific communities would be responsible, working closely with editors, publishers and health organizations, to determine whether the unique circumstances of a global pandemic and limited information would permit small, incremental observations in the nearterm while still honoring the foundations of science and its dissemination in the printed word. A real-time example and response are included in this issue of the Journal [13].

\section{A strategy to disseminate information}

The unprecedented events of December 2019 and early 2020 prompted an equally unprecedented dissemination of information. Many academic institutions turned to press releases as a rapid means to spread information, while highlighting efforts and important contributions emerging from within their walls and at the hands of faculty members. Sites for posting the findings from research studies emerged and were quickly flooded with minimally or non-peer reviewed content. Well known and highly respected medical journals accelerated the review of COVID-19 related studies to 24 to $48 \mathrm{~h}$ or less (Fig. 2), while others posted online content either prior to full peer review or galley proofing [14]. Solicited 
a

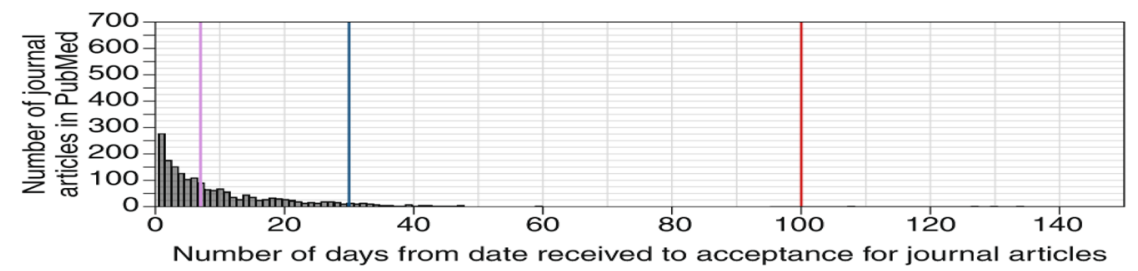

b

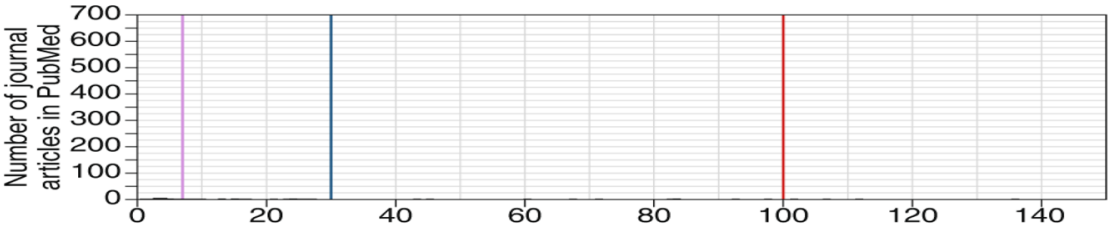

Number of days from date received to acceptance for journal articles

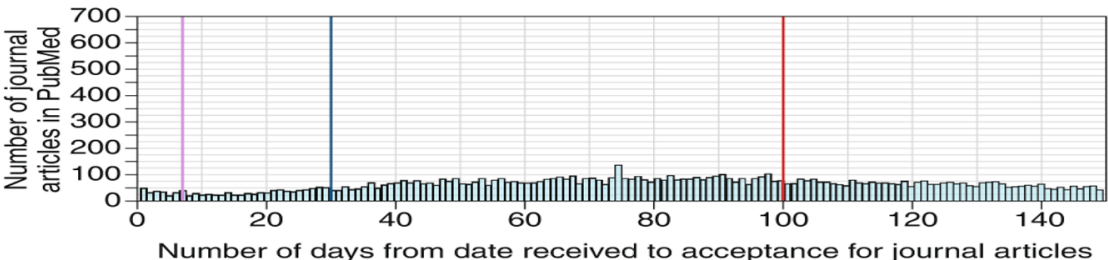

d
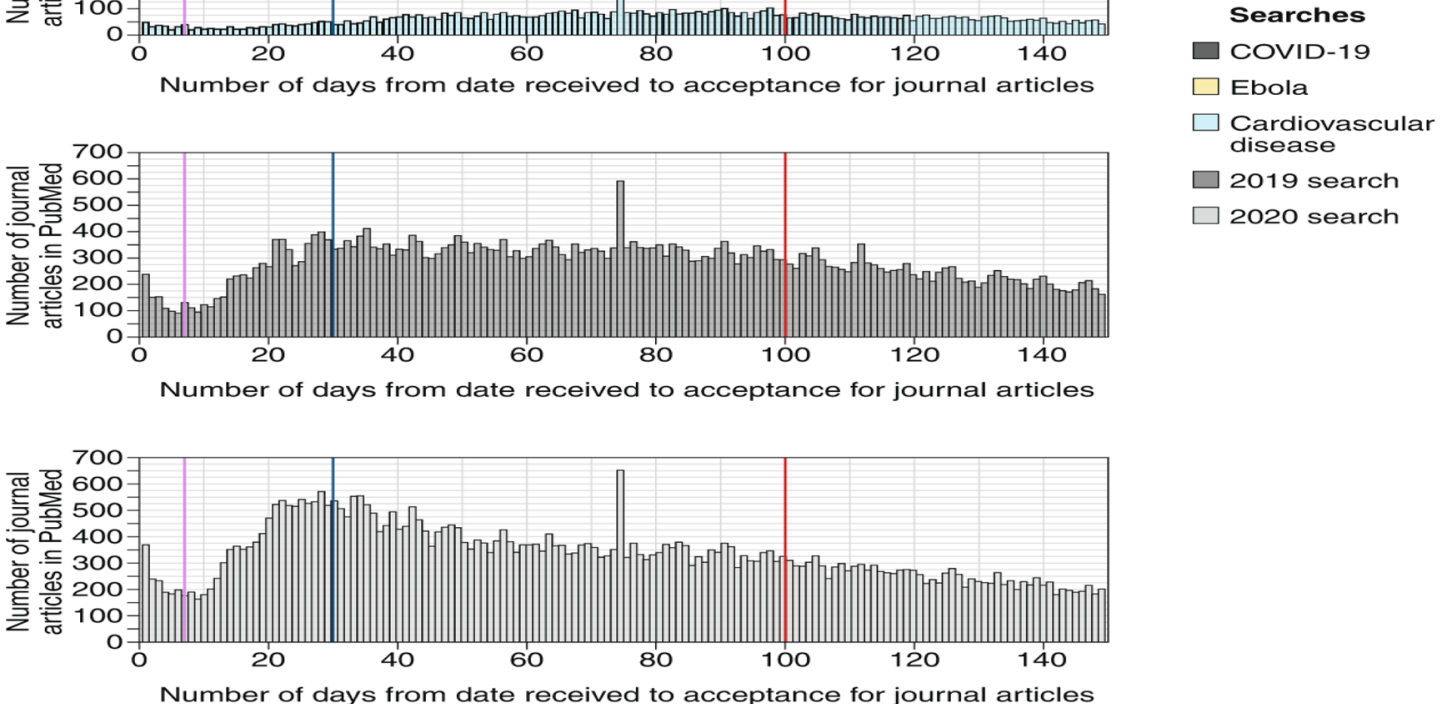

f

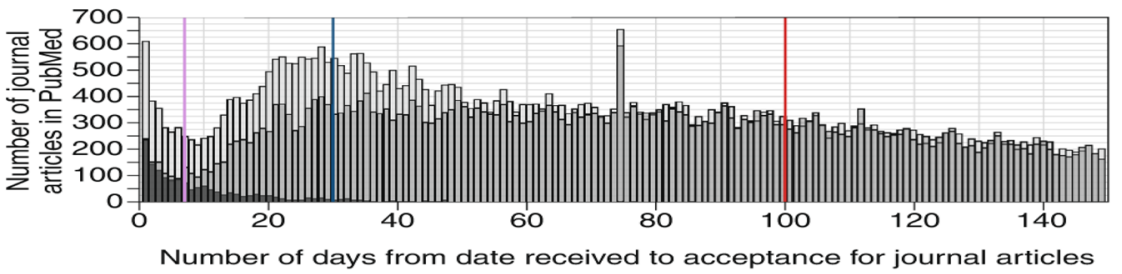

Fig. 2 Time from submission to acceptance for journal articles with received and accepted dates. a, COVID-19 articles. b, Ebola articles. c, Cardiovascular disease articles. d, Articles published in the same journals in 2019 in which COVID-19 articles were published. e, Articles published in the same journals in 2020 in which COVID19 articles were published, excluding COVID-19 articles. f, Articles

online medical journals [15] experienced a moment of virtual bliss and websites, blogs and twitter accounts of widely varied origins, implicit or explicit agendas and overarching published in the same journals in 2020 in which COVID-19 articles were published, including COVID-19 articles. In all panels, the purple line represents 7 days, the blue line 30 days and the red line 100 days from time of article receipt. From Palayew A. Nature Human Behavior 2020; 4: 666-669. With permission.

missions served up a cornucopia of information, theories and claims [16].

Accessibility of information is vital for scientific advances, however, accelerated dissemination need not call 
either quality or rigor into question if high-level processes are in place, maintained and followed. External peer reviewers must provide rigorous reviews in a timely fashion, but rapid publication is only possible if authors, medical editors, and manuscript editors are consistently in place and prepared to review and edit manuscripts daily. It also requires a skilled and experienced publishing team that can process and disseminate manuscripts quickly and accurately [14].

\section{Pace and volume of COVID-19 related publications}

A PubMed query of COVID-19 performed on 29 January 2021 yielded 97,064 results to include 261 citing's in 2019 , 89,366 citing's in 2020 and 12,187 citing's in 2021 (Pubmed.ncbi.nim.nih.gov; accessed 29 January 2021). COVID19 citing's included the following article types: clinical trials (423), reviews $(10,873)$, systemic reviews (1683), meta-analysis (626), and randomized controlled trials (220).

Google Scholar ${ }^{\mathrm{TM}}$, a bibliographic database across an array of publishing formats ranging from peer-reviewed publications, books, conference proceedings, theses and dissertations, technical reports and patents currently houses 3,540,000 results (scholar.google.com; accessed 29 January 2021).

Preprints of COVID-19 in MedRx IV and BioRx IV represented nearly $40 \%$ of all English-language COVID-19 scientific corpus in the early stage of the pandemic $(6000$ pre-prints from 16,000 articles). By August of 2020, the proportion of pre-prints decreased to $28 \%$ of all articles (Lachapelle F. MedRxIV 2020). Lachapelle proposed a measure of COVID-19 preprint publication rate using the COVID-19 open research dataset (CORD-19)—a database that includes preprints from ArXIV, BioRxIV and MedRXIV. The available information suggests that $\sim 50 \%$ of pre-print uploads are published in peer-review venues over a 6-month period. Is this rate good, encouraging, reassuring or alarming? What impact (favorable or non-favorable) do uploads ultimately deemed unacceptable for peer-review publication have on the field? What the scientific quality is of uploads that transition to peer review publications during a pandemic remains unclear.

Zdravkovic et al. [17] assessed the scientific quality of publications in the highest impact medical journals during the early phase of the pandemic. A hierarchal level of evidence was determined for COVID-19 and non-COVID-19 related original articles. Non-COVID-19 publications were associated with higher levels of evidence employing an evidence pyramid. The quantitative quality score was significantly higher in non-COVID-19 publications. Early citation rates were greater in COVID-19 publications (45 [30-344] vs. $2[1-4] ; \mathrm{p}<0.001)$.
The observations underscore intense interest, accelerated peer-review, rapid recommendations, and an unprecedented commitment to disseminating information among the most highly respected medical journals. They equally underscore a "need-to-know" moment in medical history.

Retraction Watch is an online, open-access, resource that tracks scientific processes and accountability in research. At the time of this writing, there were 72 retracted COVID-19 papers, including publications in the New England Journal of Medicine, The Lancet and Cellular Medicine and Molecular Immunology among others. In some instances, withdrawal of pre-prints occurred within 1-2 months. There where temporary retractions of five papers either without explanation or because of concern. The overall rate of retraction during COVID-19 was higher than other viral epidemics and pandemics, but does not surpass the expected or basal level in scientific publications of 4 per 10,000 papers [18]. Do the number of retractions actually represent proof of success for the process of global peer review? Can one conclude that widely available information is perhaps the most transparent and powerful opportunity to have many "critical eyes" on the published (and pre-published) literature? Is more and faster access to information the key to addressing time sensitive questions of unparalleled import?

\section{A point of clarity}

A series of thoughtful steps and an expected yet seemingly long-awaited point of clarity followed the initial reflex and response in the published literature to the COVID-19 pandemic. Medical publishers banded together with their editors, managing editors, deputy editors and stakeholders, paused, reflected and acted. The result was a comprehensive offering of access to information for students, researchers, medical professionals and the lay community in COVID19 and non-COVID-19-related content. A call to action for learning across ages, disciplines, countries, cultures and languages emerged. Digital content, remote learning arrangements, global libraries, free upgrades, unlimited access arrangements and teaching resources, book share easy-to-read formats, read-aloud videos and live-streamed events and availability of publisher repositories in text and machine-readable formats (Association of American Publishers, www.publishers.org/aap; accessed 29 January 2021). We believe that these actions "elevate all ships on open waters", heighten awareness for the power of knowledge, raise the bar for scientists and non-scientists alike to educate one-another and place the emphasis of medical research and published information squarely on efforts to teach and translate for the good of humanity. We also believe that the path will help build trust in science at this critical moment in time. 


\section{Where are we now?}

Deep and comprehensive observations continue to play an important role in the COVID-19 pandemic. A key distinction between the early experience and current undertakings is hypothesis-based research, investigative networks and randomized controlled trials. A few examples of tangible advances include evidence-based treatments such as remdesivir [19], corticosteroids [20], monoclonal antibodies [21, 22] and most recently vaccines [23-25]. Rapid distribution and public uptake, coupled with ongoing efforts of containment will secure a future for SARS-COV-2 that follows an identical course to smallpox and polio [26, 27].

There are currently 4609 studies of COVID-19 and approximately 50 of anticoagulation/antithrombotic therapy in COVID-19 registered in Clinicaltrials.gov (accessed 29 January 2021). Some have completed enrollment, while others are either ongoing or preparing for enrollment to begin. In a majority of studies, unfractionated heparin (prophylactic dose, treatment dose), low molecular weight heparin (prophylactic dose, treatment dose), direct oral anticoagulants (prophylactic or treatment dose for venous thromboembolism, standard of care, or placebo), direct intravenous anticoagulants (argatroban), aspirin and platelet P2Y2 receptor antagonists are being tested for outcomes, including in-hospital mortality, days free of organ support, duration of hospitalization and thrombotic events. Safety is determined using the International Society on Thrombosis and Hemostasis (ISTH) bleeding scale and the incidence of heparin induced thrombocytopenia (when appropriate based on treatment arms). Several studies will test out-of-hospital intervention to determine the efficacy and safety of direct oral anticoagulants, with hospitalization, rehospitalization, thrombotic events and bleeding as primary outcome measures.

The publication in the Journal of Thrombosis and Thrombolysis referenced earlier is an exemplar of evolving processes of information dissemination during the COVID-19 pandemic [28]. The investigators, based on observational data, followed by comparative cohortderived data concluded that patients with COVID-19 pneumonia compared to those with non-COVID-19 pneumonia had higher mortality. They also concluded that anticoagulation reduced mortality, particularly in patients with a high D-dimer level. Randomized trials have subsequently shown that full dose anticoagulant therapy decreases the need for organ support and improves outcome in hospitalized, moderate severity patients (NIH.gov accessed 29 January 2021).

The emphasis of a robust portfolio of ongoing clinical trials at the current stage of the pandemic rests on randomized treatment arms, hard clinical endpoints and adaptive designs to gather information rapidly. Accordingly, clinicians can expect robust data in the published literature and evidence fit for guiding patient care.

\section{What have we learned?}

This is a critical question with many layers for humanity to ponder. Medical and scientific publishing is a thermostat, bell weather, litmus test and vehicle for the human condition and its response to our environment. The COVID-19 pandemic rages on, yet through astute observations, hypothesis testing, collaboration, scientific rigor, honesty, transparency, dissemination of information using the tenets of medical publishing and the translation of ideas from bench, to bedside, to the community and to every person, we will persevere.

Last, while the focus of our editorial is medical publishing during the COVID-19 pandemic, academic institutions and researchers are the "stewards of scientific integrity and its dissemination". The research quality framework employed widely to include our respective institutions emphasizes values, ethics and integrity. It also underscores the importance of science and publishing as a continuum in academia to inform and serve.

It is a matter of primary importance in the cultivation of sciences in which truth is discoverable by the human intellect that the investigator should be free, independent, unshackled in her or his movement.

John Henry Newman.

\section{References}

1. Huang C, Wang Y, Li X, Ren L, Zhao J, Hu Y, Zhang L, Fan G, Xu J, Gu X, Cheng Z, Yu T, Xia J, Wei Y, Wu W, Xie X, Yin W, Li H, Liu M, Xiao Y, Gao H, Guo L, Xie J, Wang G, Jiang R, Gao Z, Jin Q, Wang J, Cao B (2020) Clinical features of patients infected with 2019 novel coronavirus in Wuhan, China. Lancet (Lond, Engl) 395:497-506

2. Zhu N, Zhang D, Wang W, Li X, Yang B, Song J, Zhao X, Huang B, Shi W, Lu R, Niu P, Zhan F, Ma X, Wang D, Xu W, Wu G, Gao GF, Tan W (2020) A novel coronavirus from patients with pneumonia in China, 2019. N Engl J Med 382:727-733

3. Becker RC (2020) Toward understanding the 2019 coronavirus and its impact on the heart. J Thromb Thrombolysis 50:33-42

4. Kelly J, Sadeghieh T, Adeli K (2014) Peer review in scientific publications: benefits, critiques, \& a survival guide. EJIFCC 25:227-243

5. Milne I (2002) The royal college of physicians of Edinburgh's 300 -year relationship with print on paper. Vesalius: acta Int Historiae Med 8:53-55

6. Altman LK (1996) The Ingelfinger rule, embargoes, and journal peer review—part 1. Lancet (Lond, Engl) 347:1382-1386

7. Desjardins-Proulx P, White EP, Adamson JJ, Ram K, Poisot T, Gravel D (2013) The case for open preprints in biology. PLoS Biol 11:e1001563 
8. Becker RC (2020) Covid-19 treatment update: follow the scientific evidence. J Thromb Thrombolysis 50:43-53

9. Clary EG, Tesser A (1983) Reactions to unexpected events: the naive scientist and interpretive activity. Pers Soc Psychol Bull 9:609-620

10. Dungan JA, Stepanovic M, Young L (2016) Theory of mind for processing unexpected events across contexts. Soc Cognit Affect Neurosci 11:1183-1192

11. Reisenzein R, Horstmann G, Schützwohl A (2019) The cognitiveevolutionary model of surprise: a review of the evidence. Top Cognit Sci 11:50-74

12. Liebman MN, Marincola FM (2012) Expanding the perspective of translational medicine: the value of observational data. J Transl Med 10:61-61

13. Yin S, Huang M, Li D, Tang N (2020) Difference of coagulation features between severe pneumonia induced by SARS-CoV2 and non-SARS-CoV2. J Thromb Thrombolysis. https://doi. org/10.1007/s11239-020-02105-8

14. Bauchner H, Fontanarosa PB, Golub RM (2020) Editorial evaluation and peer review during a pandemic: how journals maintain standards. JAMA 324:453-454

15. Becker RC, Cotarlan V, Sadayappan S (2019) The rapid proliferation of solicited content online journals: a quest to disseminate knowledge? J Thromb Thrombolysis 47:337-344

16. Agley J, Xiao Y, Thompson EE, Golzarri-Arroyo L (2020) COVID-19 misinformation prophylaxis: protocol for a randomized trial of a brief informational intervention. JMIR Res Protoc $9: \mathrm{e} 24383$

17. Zdravkovic M, Berger-Estilita J, Zdravkovic B, Berger D (2020) Scientific quality of COVID-19 and SARS CoV-2 publications in the highest impact medical journals during the early phase of the pandemic: a case control study. PLoS ONE 15:e0241826

18. Yeo-Teh NSL, Tang BL (2019) An alarming retraction rate for scientific publications on coronavirus disease (COVID-19). Acc Res 28(1):1-7

19. Beigel JH, Tomashek KM, Dodd LE, Mehta AK, Zingman BS, Kalil AC, Hohmann E, Chu HY, Luetkemeyer A, Kline S, Lopez de Castilla D, Finberg RW, Dierberg K, Tapson V, Hsieh L, Patterson TF, Paredes R, Sweeney DA, Short WR, Touloumi G, Lye DC, Ohmagari N, Oh M-D, Ruiz-Palacios GM, Benfield T, Fätkenheuer G, Kortepeter MG, Atmar RL, Creech CB, Lundgren J, Babiker AG, Pett S, Neaton JD, Burgess TH, Bonnett T, Green M, Makowski M, Osinusi A, Nayak S, Lane HC, Members A-SG (2020) Remdesivir for the treatment of Covid-19-final report. N Engl J Med 383:1813-1826

20. Sterne JAC, Murthy S, Diaz JV, Slutsky AS, Villar J, Angus DC, Annane D, Azevedo LCP, Berwanger O, Cavalcanti AB, Dequin PF, Du B, Emberson J, Fisher D, Giraudeau B, Gordon AC, Granholm A, Green C, Haynes R, Heming N, Higgins JPT, Horby P, Jüni P, Landray MJ, Le Gouge A, Leclerc M, Lim WS, Machado FR, McArthur C, Meziani F, Møller MH, Perner A, Petersen MW, Savovic J, Tomazini B, Veiga VC, Webb S, Marshall JC (2020)
Association between administration of systemic corticosteroids and mortality among critically ill patients with COVID-19: a meta-analysis. JAMA 324:1330-1341

21. Wang C, Li W, Drabek D, Okba NMA, van Haperen R, Osterhaus ADME, van Kuppeveld FJM, Haagmans BL, Grosveld F, Bosch B-J (2020) A human monoclonal antibody blocking SARS-CoV-2 infection. Nat Commun 11:2251

22. Wan J, Xing S, Ding L, Wang Y, Gu C, Wu Y, Rong B, Li C, Wang S, Chen K, He C, Zhu D, Yuan S, Qiu C, Zhao C, Nie L, Gao Z, Jiao J, Zhang X, Wang X, Ying T, Wang H, Xie Y, Lu Y, Xu J, Lan F (2020) Human-IgG-neutralizing monoclonal antibodies block the SARS-CoV-2 infection. Cell Rep 32:107918

23. Jackson LA, Anderson EJ, Rouphael NG, Roberts PC, Makhene M, Coler RN, McCullough MP, Chappell JD, Denison MR, Stevens LJ, Pruijssers AJ, McDermott A, Flach B, Doria-Rose NA, Corbett KS, Morabito KM, O'Dell S, Schmidt SD, Swanson PA, Padilla M, Mascola JR, Neuzil KM, Bennett H, Sun W, Peters E, Makowski M, Albert J, Cross K, Buchanan W, Pikaart-Tautges R, Ledgerwood JE, Graham BS, Beigel JH (2020) An mRNA vaccine against SARS-CoV-2 - preliminary report. N Engl J Med 383:1920-1931

24. Anderson EJ, Rouphael NG, Widge AT, Jackson LA, Roberts PC, Makhene M, Chappell JD, Denison MR, Stevens LJ, Pruijssers AJ, McDermott AB, Flach B, Lin BC, Doria-Rose NA, O'Dell S, Schmidt SD, Corbett KS, Swanson PA, Padilla M, Neuzil KM, Bennett H, Leav B, Makowski M, Albert J, Cross K, Edara VV, Floyd K, Suthar MS, Martinez DR, Baric R, Buchanan W, Luke CJ, Phadke VK, Rostad CA, Ledgerwood JE, Graham BS, Beigel JH (2020) Safety and immunogenicity of SARS-CoV-2 mRNA1273 vaccine in older adults. N Engl J Med 383:2427-2438

25. Polack FP, Thomas SJ, Kitchin N, Absalon J, Gurtman A, Lockhart S, Perez JL, Pérez Marc G, Moreira ED, Zerbini C, Bailey R, Swanson KA, Roychoudhury S, Koury K, Li P, Kalina WV, Cooper D, Frenck RW, Hammitt LL, Türeci Ö, Nell H, Schaefer A, Ünal S, Tresnan DB, Mather S, Dormitzer PR, Şahin U, Jansen KU, Gruber WC (2020) Safety and efficacy of the BNT162b2 mRNA Covid-19 vaccine. N Engl J Med 383(27):2603-15

26. Meldrum M (1998) "A calculated risk": the Salk polio vaccine field trials of 1954. BMJ 317:1233-1236

27. Riedel S (2005) Edward Jenner and the history of smallpox and vaccination. Proc (Bayl Univ Med Cent) 18:21-25

28. Aid M, Busman-Sahay K, Vidal SJ, Maliga Z, Bondoc S, Starke C, Terry M, Jacobson CA, Wrijil L, Ducat S, Brook OR, Miller AD, Porto M, Pellegrini KL, Pino M, Hoang TN, Chandrashekar A, Patel S, Stephenson K, Bosinger SE, Andersen H, Lewis MG, Hecht JL, Sorger PK, Martinot AJ, Estes JD, Barouch DH (2020) Vascular disease and thrombosis in SARS-CoV-2-infected rhesus macaques. Cell 183(1354-1366):e13

Publisher's Note Springer Nature remains neutral with regard to jurisdictional claims in published maps and institutional affiliations. 